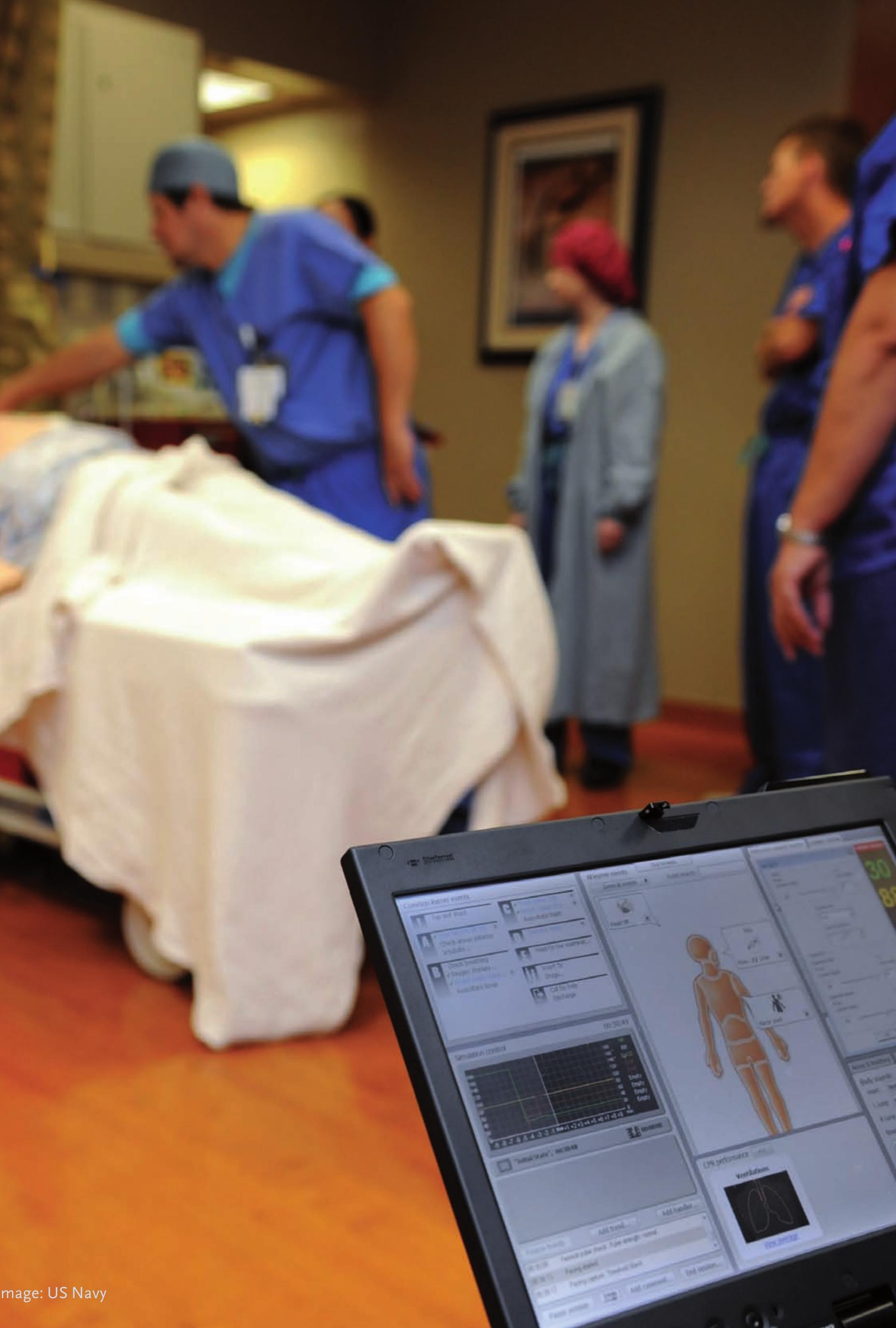




\begin{tabular}{|c|c|c|c|}
\hline$\Omega$ & 0 & $\equiv$ & \\
\hline $\begin{array}{l}\text { Alanna Hare, } \\
\text { Anita Simonds }\end{array}$ & $\begin{array}{l}\text { Royal Brompton and } \\
\text { Harefield, Sleep and } \\
\text { Ventilation, London, UK }\end{array}$ & $\begin{array}{l}\text { A. Hare: Royal Brompton } \\
\text { and Harefield, NHS } \\
\text { Foundation Trust, Sleep and } \\
\text { Ventilation, Sydney Street, } \\
\text { London, SW3 6NP, UK }\end{array}$ & a.hare@rbht.nhs.uk \\
\hline
\end{tabular}

\section{Simulation-based education for non-invasive ventilation}

\section{Simulation-based education}

Simulation has been defined as "a technique, not a technology, to replace or amplify real experiences with guided experience, often immersive in nature, that evokes or replicates substantial aspects of the real world in a fully interactive fashion" [1].

Simulation-based medical education can therefore be defined as any educational activity which uses simulated components to replicate clinical practice [2] and where the learner is required to respond to the clinical problems presented "as he or she would under natural circumstances" [3]. Simulation-based education exists in many forms, including simulated and virtual patients, static and interactive mannequins, part-task trainers, computer-based physiology simulators, computer-rendered virtual cadavers (for example, the Visible Human Project [4]), and virtual reality "games". One could also add to this list the use of human cadavers, live animals and inert animal products (such as pig skin for practicing suture techniques).

\section{Background}

Although training using simulation has a long history in other high-risk industries, such as the aviation and nuclear industries and in the military, its use in the medical domain is a relatively new development. Nevertheless, there has been a dramatic increase in the number of facilities offering simulation-based training, and there is a growing acceptance of its utility in the field of medical education. There are several reasons for this increased uptake. Firstly, a rapidly changing healthcare climate has meant that increasing numbers of both undergraduate and postgraduate trainees are competing for access to fewer patients and shorter training opportunities. These changes in the organisation of medical practice have led to a fragmentation of the traditional clinical "team" structure, meaning that the dominant apprenticeship model of clinical training is becoming increasingly unsustainable. In addition, trainees are now regularly exposed to an increasing number of new and complex healthcare technologies for diagnosis and management, all of which require the acquisition of new skills and techniques for effective implementation. Furthermore, patient safety concerns $[5,6]$ mean that it is becoming increasingly unacceptable for medical students and trainee medical staff to hone these clinical skills on live patients, at least in the early stages of their learning curve. Finally, there has been a paradigm shift in medical education towards an outcomes-focused approach, driven in part by the fact that, as a public service, there is an onus upon the medical profession to provide evidence and assurance that doctors are competent to practice $[7,8]$.

Simulation-based education is able to respond to these challenges in a number of ways. By providing the opportunity for proactive curricular planning, rather than learning
Statement of Interest A. Simonds has received an educational grant from Resmed Ltd, and payment for development of educational presentations from ERS. A. Hare reports grants and non-financial support from ResMed, grants from ERS, during the conduct of the study. 
taking place on an ad hoc basis, dependent on which patients are present on the ward or in clinic at a particular time, simulation is able to bridge the emerging gap between skills and training opportunities [9]. Simulation provides a safe and controlled environment in which trainees at all levels have the opportunity to practice and refine their clinical skills whilst protecting patients from harm. Indeed, the Institute of Medicine (The National Academies, Washington, DC, USA) has advocated that the introduction of new medical technologies should be accompanied by simulation-based education and certification requirements [6]. Finally, simulation offers the possibility for competency assessment and credentialling for the attainment of professional performance through the use of benchmarking [10]. By assessing and credentialling competency, simulation-based education is able to enhance the accountability of the medical profession by assuring patients and the wider public that clinicians are skilled and proficient to carry out their medical care [5].

\section{Evidence base}

Several systematic reviews (see for example $[11,12])$ and at least two meta-analyses $[13,14]$ have investigated the effectiveness of simulation-based medical education in terms of knowledge and skills outcomes and there is now a large body of good quality research evidence which demonstrates that simulationbased education is not only effective in terms of skills acquisition (see for example [13-17]) but also that clinical skills acquired during simulation-based training translate directly into improved patient care and better clinical outcomes [17-20].

For example, BARSUK et al. [17] demonstrated reduced incidence of catheter-related bloodstream infections for trainees who had received simulator-based training on central venous catheter insertion compared with those who had not; DRAYCOTT et al. [19] have published extensive research demonstrating reduced brachial plexus injuries and neonatal hypoxicischaemic encephalopathy for births complicated by shoulder dystocia after the implementation of simulation-based training; BLUM et al. [18] have shown improved performance in bronchoscopy following a simulation-based bronchoscopy training programme; and SCHROEDL et al. [21] showed simulator-trained residents performed significantly higher on bedside skills tests of respiratory mechanics, ventilator settings and circulatory parameters than traditionally trained residents in a medical intensive care unit.

It is important to recognise, however, that simulation is not designed to replace clinical apprenticeship, but to enhance it by providing a safe environment for trainees to learn and practice their clinical skills. Simulation should be viewed as another tool for teaching and assessment which can facilitate learning and evaluation in many areas of medical education across the range of healthcare disciplines, and offers the opportunity to impact patient safety and healthcare outcomes in a positive and significant way [22].

\section{Simulation-based education and noninvasive ventilation}

Training curricula in respiratory and intensive care medicine set by the European Respiratory Society, Royal College of Physicians, UK, and other national societies specify essential experience in acute and chronic noninvasive ventilation (NIV) [23]. This is usually divided into knowledge-based aspects, skills and attitudes. While a knowledge-based programme is relatively easy to deliver via lectures and written material, practical skills-based training is more difficult to develop and apply. Nevertheless, skills-based training is vital in area where successful practical implementation of a technique is crucial. There is a pressing need for such skills-based training as there is extensive evidence that medical and nursing team members lack these skills and feel ill-prepared and unsafe to deliver NIV in accordance with guidelines [24]. This directly affects the uptake and use of NIV in institutions, so that, despite extensive evidence supporting the use of NIV across a broad range of clinical conditions, including acute exacerbations of COPD, acute cardiogenic pulmonary oedema and, in immunocompromised patients $[25,26]$, several surveys across both the USA and Europe have found wide variation in utilisation rates, from $0 \%$ to $>50 \%$ [27-30]. Data from these surveys suggest that only $10-15 \%$ of patients with COPD or chronic heart failure (CHF) receive NIV for acute 
respiratory failure. This compares to a literature which suggests usage rates for NIV in acute respiratory failure due to COPD and $\mathrm{CHF}$ should be around $70 \%$ and $20 \%$, respectively $[31,32]$. The main reasons given for lower utilisation rates in these surveys were a lack of clinician knowledge and training.

Furthermore, clinical experience with NIV seems to be a decisive factor in the success of its use. A systematic review of the predictors of NIV failure [33] found that patient tolerance of and compliance with NIV therapy is closely related to clinician expertise. The importance of clinical experience was also emphasised by GiRou et al. [31] in a study of French intensive care units which demonstrated a significant reduction in mortality and in the incidence of nosocomial pneumonia as the rate of NIV utilisation increased, changes which the authors attributed to a "learning effect". In addition, CARLUCCI et al. [34] demonstrated that increasing clinical experience with the use of NIV meant that more severely ill patients could be treated whilst maintaining a constant NIV success rate.

Taken together, these studies suggest that improving the education and training of practitioners in NIV should be a key part of any measures designed to increase NIV utilisation rates and enhance the success of NIV therapy. Delivering effective training for NIV is challenging. Conferences and lectures often have little effect in terms of changing clinical practice [35], and practical hands-on experience is more consistently successful. Medical simulation is ideally suited to this hands-on training and has previously been shown to be effective in training nursing staff in the practical use of NIV [36].

\section{A simulation-based educational tool for NIV}

Currently there is no NIV simulator model which can be used to assess the user's competence in establishing ventilator settings and understanding and correctly responding to the effect of the ventilator on patient pathophysiology and tolerance.

We, at the Royal Brompton Hospital, London, UK, supported by an unrestricted research grant and technical input from
ResMed (BellaVista, Australia), and an Educational grant from the ERS are responding to this training gap in NIV education with a web-based simulation tool and will use this tool as a basis for a full educational programme for NIV, aimed at clinicians and other allied medical professionals involved in the delivery of NIV. Our simulator is unique in that it enables the trainee to see accurately modelled patient physiological outcomes of changes in trainee-selected ventilatory settings. The educational programme includes sections on the physiological rationale for NIV and the essential modes and settings of the ventilator, and patient scenarios which take the trainee through commonly encountered clinical cases, enabling the trainee to make decisions at key stages in the patient's journey, and see the impact of those decisions on the patient's respiratory and cardiovascular status. Scenarios include acute exacerbation of chronic obstructive pulmonary disease (COPD), stable hypercapnic COPD, obesity hypoventilation and neuromuscular disease (including motor neurone disease and Duchenne muscular dystrophy). Practical tips for initiating NIV, interface selection, circuit set-up, selection and titration of settings are provided, and information on troubleshooting and the management of NIV failure are also provided at key points in each clinical case scenario.

Initial, formative, feedback on the training course during a local pilot programme was overwhelmingly positive, and more detailed feedback is now being sought in a full pilot. The course is being evaluated as part of a Masters in Technology and Simulation in Clinical Practice, supervised by colleagues at the Institute of Education, University of London, UK. A multi-methods approach to evaluation is being utilised, with pre- and post-course tests of skill forming the quantitative feedback, alongside interview and survey data providing a qualitative dimension to the research. The final educational programme will be available via the ERS website from September 2013. The aim is that this programme will provide a safe and effective environment for clinicians to develop their knowledge and skills in NIV, and in the longer term, that this will translate into increased uptake of NIV and improved clinical practice and outcomes across Europe.

\section{Educational questions}

1. The following could be described as forms of simulation-based education:

a. The use of human cadavers to teach anatomy

b. The use of a 3D representation of a human arm to each phlebotomy skills

c. The use of virtual reality "games" to

teach laparotomy

skills to trainee

surgeons

d. All of the above

2. The following are not cited as valid reasons for an increase in the use of simulation-based educational technologies:

a. A reduction in the number of training hours for clinicians in training b. An increase in the number of new and complex healthcare technologies c. The possibility of entirely replacing clinical training with training in a clinical skills laboratory

3. The following are true with regards to clinical training in non-invasive ventilation:

a. Patient tolerance of NIV is not related to the clinical experience of the treating clinician 
b. Survey evidence suggests medical and nursing staff feel ill-prepared to deliver NIV according to guidelines c. Conferences and lectures are effective in terms of changing clinical practice
Key points

- Simulation-based education refers to any educational activity which uses simulated components to replicate clinical practice

- A changing healthcare climate with shorter training opportunities has created an emerging "skills gap" in which the traditional model of apprenticeship learning is increasingly unsustainable

- Evidence suggests simulation-based education is effective in terms of clinical skills acquisition and that these skills translate into improved patient care and clinical outcomes

- We are developing a new web-based simulation tool for training in noninvasive ventilation in order to provide a safe and effective environment for clinicians to develop their knowledge and skills in NIV

\section{References}

1. Gaba DM. The future vision of simulation in healthcare. Simul Healthc 2007; 2: 126-135.

2. Ziv A, Ben-David S, Ziv M. Simulation based medical education: an opportunity to learn from errors. Med Teach 2005; 27: 193-199.

3. McGaghie WC. Simulation in professional competence assessment: basic considerations. In: A Tekian, C McGaghie W McGaghie, Eds. Innovative simulations for assessing professional competence. Chicago, Department of Medical Education, University of Illinois at Chicago, 1999.

4. US National Library of Medicine. The Visible Human Project. Available from: www.nlm.nih.gov/research/ visible/ Date last updated June 19, 2013, date last accessed: July 16, 2013.

5. Ziv A, Wolpe PR, Small SD, et al. Simulation-based medical education: an ethical imperative. Acad Med 2003; 78: 783-788.

6. Kohn LT, Corrigan JM, Donaldson MS, Eds. To err is human: building a safer healthcare system. Washington DC, National Academy Press, 2000.

7. Carraccio C, Wolfsthal SD, Englander R, et al. Shifting paradigms: from Flexner to competencies. Acad Med 2002; 77: 361-367.

8. Kilroy DA. Competency in the new language of medical education. Emerg Med 2009; 26: 3-6.

9. Steketee C, Bower A. Augmenting the clinical apprenticeship model. AARE International Educational Research Conference; Fremantle 2007.

10. Michelson JD, Manning L. Competency assessment in simulation-based procedural education. Am J Surg 2008; 196: 609-615.

11. Issenberg SB, McGaghie WC, Petrusa ER. Features and uses of high-fidelity medical simulations that lead to effective learning: a BEME systematic review. Med Teach 2005; 27: 10-28.

12. McGaghie WC, Issenberg SB, Petrusa ER, et al. Effect of practice on standardised learning outcomes in simulation-based medical education. Med Educ 2006; 40: 792-797.

13. Cook DA, Hatala R, Brydges R, et al. Technologyenhanced simulation for health professions educa tion: a systematic. JAMA 2011; 306: 978-988.

14. McGaghie WC, Issenberg SB, Cohen ER, et al. Does simulation-based medical education with deliberate practice yield better results than traditional clinical education? A meta-analytic comparative review of the evidence. Acad Med 2011; 86: 706-711.

15. Colt HG, Crawford SW, Galbraith O zrd. Virtual reality bronchoscopy simulation: a revolution in procedural training. Chest 2001; 120: 1333-1339.

16. Wayne DB, Butter J, Siddall VJ, et al. Simulationbased training of internal medicine residents in advanced cardiac life support protocols: a randomized trial. Teach Learn Med 2005; 17: 210-216.

17. Barsuk JH, Cohen ER, Feinglass J, et al. Use of simulation-based education to reduce catheterrelated bloodstream infections. Arch Intern Med 2009; 169: 1420-1423.

18. Blum MG, Powers TW, Sundaresan S. Bronchoscopy simulator effectively prepares junior residents to competently perform basic clinical bronchoscopy. Ann Thorac Surg 2004; 78: 287-291.

19. Draycott TJ, Crofts JF, Ash JP, et al. Improving neonatal outcome through practical shoulder dystocia training. Obstet Gynecol 2008; 112: 14-20.

20. Seymour NE, Gallagher AG, Roman SA, et al. Virtual reality training improves operating room performance: results of a randomized, double-blinded study. Ann Surg 2002; 236: 458-463.

21. Schroed C), Corbridge TC, Cohen ER, et al. Use of simulation-based education to improve resident learning and patient care. J Crit Care 2012; 27: 219.

22. Scalese RJ, Obeso VT, Issenberg SB. Simulation technology for skills training and competency assessment in medical. J Gen Intern Med 2008; 23: Suppl. 1, 46-49.

23. Loddenkemper R, Severin T, Haslam PL. European curriculum recommendations for training in adult respiratory medicine: crossing boundaries with HERMES. Eur Respir J 2008; 32: 538-540.

24. Plumb J, Juszczyszyn M, Mabeza G. Non-invasive ventilation (NIV) a study of junior doctor competence. Open Med Educ J 2010; 3: 11-17.

25. International Consensus Conferences in Intensive Care Medicine. noninvasive positive pressure ventilation in acute respiratory failure. Am J Respir Crit Care Med 2001; 163: 283-291.

26. British Thoracic Society Standards of Care Committee. Non-invasive ventilation in acute respiratory failure. Thorax 2002; 57: 192-211. 
27. Maheshwari V, Paioli D, Rothaar R, et al. Utilization of noninvasive ventilation in acute care hospitals: a regional survey. Chest 2006; 129: 1226-1233.

28. Doherty MJ, Greenstone MA. Survey of non-invasive ventilation (NIPPV) in patients with acute exacerbations of chronic obstructive pulmonary disease (COPD) in the UK. Thorax 1998; 53: 863-866.

29. Vanpee D, Delaunois L, Lheureux $P$, et al. Survey of non-invasive ventilation for acute exacerbation of chronic obstructive pulmonary disease patients in emergency departments in Belgium. Eur J Emerg Med 2002; 9: 217-224.

30. Carlucci A, Richard JC, Wysocki M, et al. Noninvasive versus conventional mechanical ventilation. An epidemiologic survey. Am J Respir Crit Care Med 2001; 163: 874-880.

31. Girou E, Brun-Buisson C, Taille S, et al. Secular trends in nosocomial infections and mortality associated with noninvasive ventilation in patients with exacerbation of COPD and pulmonary edema. JAMA 2003; 290: 2985-2991.

32. Demoule A, Girou E, Richard JC, et al. Increased use of noninvasive ventilation in French intensive care units. Intensive Care Med 2006; 32: 1747-1755.

33. Nava S, Ceriana P. Causes of failure of noninvasive mechanical ventilation. Respir Care 2004; 49: 295-303.

34. Carlucci A, Delmastro M, Rubini F, et al. Changes in the practice of non-invasive ventilation in treating COPD patients over 8 years. Intensive Care Med 2003; 29: 419-425.

35. Burns KE, Sinuff T, Adhikari NK, et al. Bilevel noninvasive positive pressure ventilation for acute respiratory failure: survey of Ontario practice. Crit Care Med 2005; 33: 1477-1483.

36. McQueen S, Dickinson M, Pimblett M. Human patient simulation can aid staff training in noninvasive ventilation. Nurs Times 2010; 106: 20.

\section{Suggested answers}

1. d.

2. c.

3. $b$ 